\title{
Olhar fracionado e face expressionista: a construção da personagem em Samuel Rawet
}

\author{
Fractionated look and expressionist face: the construction of the character in Samuel Rawet
}

\author{
Maria Isabel Edom Pires
}

Universidade de Brasília - Goiás - Brasil

$\diamond$

\begin{abstract}
Resumo: $\mathrm{O}$ artigo visa discutir a presença das artes plásticas e da fotografia na construção da personagem Ida do conto "A prece" de Samuel Rawet. Pergunta-se sobre o significado do emprego de diversos recursos de picturalidade, notadamente as alusões ao Cubismo e ao Expressionismo, para narrar a história da imigrante judia. Questiona-se o motivo pelo qual ela é vista e mostrada de forma seccionada e deformada. Com base nas teorias sobre translação e transposição entre artes (Moser, Clüver, Louvel), aponta-se para alguns sentidos pelos quais se passa de uma arte a outra, entendendo o tema da imigração como o catalizador de muitos deles.
\end{abstract}

Palavras-chave: Artes plásticas; Samuel Rawet; Translação; Imigração

\begin{abstract}
The article aims to discuss the presence of painting and photography in the construction of the character Ida of the short story "A prece" by Samuel Rawet. We ask about the meaning of the use of various resources of painting, notably the allusions to Cubism and Expressionism, to narrate the story of the Jewish immigrant. It is questioned why she is seen and shown in a sectioned and deformed form. Based on the theories of translation and transposition between arts (Moser, Clüver, Louvel), we point to some meanings from one art to another, understanding the subject of immigration as the catalyst for many of them.
\end{abstract}

Keywords: Visual arts; Samuel Rawet; Translation; Immigration

\section{Introdução}

Quando olhada de face, era um abril. Quando olhada de lado, era um agosto. Duas mulheres numa: tinha o rosto Gordo de frente, magro de perfil.

(MANUEL BANDEIRA, "Peregrinação")

Apontam os versos de Bandeira para o olhar fragmentado de quem observa uma mulher. Esse destaque visual sugere a comparação entre poesia e artes plásticas, presente desde a Arte Poética de Horácio (ut pictura poesis, assim como a pintura a poesia). É para uma tela cubista que somos direcionados em uma primeira instância. O todo aí nos é revelado pela secção: a face, o perfil, a frente, o lado da personagem bandeiriana. Para além da tela, encontram-se alguns princípios da vanguarda cubista: o desmonte do objeto para apresentálo em variados ângulos, oferecendo a contemplação do todo por intermédio das partes. É Gilda de Melo e
Sousa quem comenta sobre a relação do poema com o cubismo:

É como se a nitidez cortante da percepção cubista satisfizesse àquela parte do seu temperamento que, oposta à face fantástica e ilógica, ansiava pela ordem e pela clareza visual. "Maçã", Água-forte", "Carta de brasão" são poesias construídas segundo a mesma técnica de oposição marcante de cores ou de superfícies, de espaços plenos e espaços vazios alternando-se secamente, sem o recurso tradicional das "passagens":

O preto no branco

$\mathrm{O}$ pente na pele

Escudo vermelho nele uma Bandeira

Quadrada de ouro

E nele um leão rompente

Azul, armado

(GILDA e ANTONIO CANDIDO, 1993, p. 10). 
Bandeira, como outros modernistas, realizaram transposições entre várias artes, como sugeriam as vanguardas do início do século XX.

Os estudos interartes, muito presentes em decorrência dessa aproximação geral propiciada pelos movimentos artísticos internacionais, têm uma longa trajetória avaliada por Clüver (2008) e Moser (2006) até o entendimento atual do conceito de intermidialidade. Com longa tradição no Comparativismo, o estudo interartes, reavisto por Moser (2006) com a finalidade de traçar uma arqueologia da intermidialidade, pode ser averiguado nos níveis "da produção, do artefato em si ou dos processos de recepção e conhecimento" (idem, p.43). Com base no estudo de Lessing (apud Moser, p. 44), cujo trabalho sobre poesia e pintura, enfatiza ora sua realização (a poesia seria uma arte no tempo; a pintura, a arte do espaço, por exemplo); ora seu objeto (a poesia prevê o desenvolvimento de uma ação; a pintura, um corpo dentro do espaço); e nos seus meios ("sons articulados no tempo", para a poesia; "figuras e cores dentro do espaço", para a pintura), Moser pergunta sobre "as zonas cinzentas, os objetos recalcitrantes, restos e rejeitos" (p.45), ou seja, sobre o que não entra na lógica binária do dramaturgo alemão. Além de inventariar as transgressões do autor a sua própria lei, como a de que a representação de um objeto na pintura pode ser um momento condensado que aponta para uma "potencialidade mais vasta" (p.46), Moser analisa outros casos e demonstra as suas transgressões às leis de Lessing, estudando a linguagem visual de Blake, as relações entre música e literatura de Hoffmann, e a remediação fílmica da pintura em Derek Jarman e Jean-Luc Godard. Para a investigação de Moser, a revisão da tradição dos estudos interartes e daquilo que neles não cabe oferece a oportunidade de estudar a midialidade em um contexto intermidiático, como é o do presente (p. 64).

Importantes para a compreensão das relações interartes também são os estudos de Clüver (1997) que recorre à crítica e à teoria literária para uma revisão diacrônica dos estudos literários. Sobre os estudos realizados do poema "Saint" de Mallarmé, Clüver critica pesquisas que meramente sugerem que a imagem serviu de inspiração para um poema ou de que a arte visual foi verbalizada, destacando como relevante a posição do leitor ao reconhecer que quanto mais amplo for seu acervo, melhores condições terá de usufruir do poema, tomado como exemplo de que existe algo de revelador na presença de intertextos musicais e pictoriais na leitura de textos verbais, cujo reconhecimento depende do repertório cultural e de leitura do receptor (idem, p.40). O autor trata de um leitor capaz de restabelecer a relevância da intertextualidade entre as artes, o que levaria a questões como: "reconstrução das preocupações e programas estéticos, dos modos de representação, das convenções estilísticas e estruturais relevantes para o artista, seus modelos negativos ou positivos" (p.41). $\mathrm{O}$ autor admite um retorno à "imagologia", ou seja, às representações ou ao modo como são representadas as imagens do estrangeiro ("l'étranger tel qu'on le voit"), (p.51). Destaca igualmente o próprio questionamento feito aos estudos interartes, hoje pensados como práticas sociais. Conclui por mais adequado o estudo interartes se concebido como "discurso transdisciplinar às voltas com as artes" (p. 52), com orientação semiótica sem a exclusão dos contextos culturais. Em artigo de 2008, Clüver adere francamente à intermidialidade como um campo transdisciplinar que abarca os estudos intermídias; as artes outrora estudadas pelos estudos interartes tradicionais; estudos multimídias; e estudos mixmídias (2008, p.218). Vale ressaltar, para o efeito deste artigo, a afirmação de que a inclusão dos estudos interartes aos estudos da intermidialidade surge "tanto da percepção das gradativas mudanças na orientação teórica e nas práticas do discurso interdisciplinar quanto da aproximação entre as áreas dos estudos interartes e dos estudos das mídias" (2008, p. 212). Por fim, Clüver também cita o trabalho divisor de águas de Lessing, Laocoonte, ou sobre os limites da pintura e da poesia, escrito em 1766, o qual estabeleceu a distinção entre a representação literária, baseada no tempo e, assim, na representação sucessiva, e a representação na pintura, baseada no espaço e, assim, na percepção simultânea. Dele derivaram estudos sobre as propriedades espaciais no texto literário e aspectos temporais em textos visuais (2008, p. 215).

Já Liliane Louvel (2006) trata sobre o aspecto da translação pictural, qual seja a passagem da linguagem pictural para a linguagem verbal, e aponta três categorias por meio das quais se percebe essa passagem: a descrição de um quadro real; a descrição de um quadro fictício e a descrição com valor pictural que traz vários indicadores da picturalidade. Dos marcadores arrolados pela autora, destacar: 1) o enquadramento; 2) a presença de personagem voyeur; 3) a modalização; e 4) a presença de um léxico especializado. Também concebe a autora a noção de iconotexto: "a presença de uma imagem visual convocada pelo texto e não somente a utilização de uma imagem visível para ilustração ou como ponto de partida criativo" (LOUVEL, 2006, p. 218).

$\mathrm{O}$ conto em questão pode ser lido a partir desse efeito da translação se nele marcarmos os elementos da picturalidade de que fala Louvel (2006), se pensarmos sobre as zonas cinzentas, os objetos recalcitrantes, aquilo que transgride as leis dos trabalhos tradicionais sobre pintura e poesia (MOSER, 2006) e se anotarmos a orientação de Clüver (2008) para quem os estudos interartes, concebidos como "discurso transdisciplinar às voltas com as artes", não deve excluir os contextos culturais. 


\section{Fracionamento e Cubismo}

A protagonista nos é apresentada de modo fracionado: "xale preto envolto no pescoço, mãos duras retesadas ao longo do corpo" (RAWET, 2004, p.31); “o giro do corpo despejou-lhe um olhar pálido e a aboca crispada" (ibid., p.32); "cotovelos nos joelhos" (p.31); "face na palma das mãos" (p.31). Não é senão por meio de aspectos visuais em concepção cubista que se apresenta a personagem feminina imigrante do livro Contos do imigrante de Samuel Rawet. Judeu polonês chegado ao Brasil ainda menino em 1929, ele viveu no Rio de Janeiro de onde saiu aos 28 anos para Brasília, já formado em Engenharia, para participar da equipe de Oscar Niemeyer na construção da capital. Ali viveu como engenheiro e escritor até sua morte em 1984, aos 55 anos. Nesse seu primeiro livro de contos, publicado em 1956, de um total de dez contos, cinco lidam diretamente com o tema da imigração judaica para o Brasil em decorrência das guerras ${ }^{1}$. "A prece", o segundo deles, narra a vinda de Ida, uma mulher idosa que perdera os parentes na guerra, e a sua tentativa de adaptação no Brasil em um casarão onde é francamente hostilizada. A cena inicial revela a chegada de Ida ao casarão depois de um exaustivo dia de trabalho como mascate. Em terceira pessoa, o conto segue inicialmente o olhar dos moleques que, já na rua, passam a incomodá-la. Os personagens voyeurs nunca a veem na sua totalidade, em parte porque têm medo dela, em parte porque a consideram uma estranha, uma observação não exclui a outra:

- Aí a velha aí!

... só lhe viam o perfil marcado e os cabelos grisalhos, repuxados em coque...

Nunca tiveram coragem de olhá-la de frente, e quando lhe atiraram a primeira pedra, raspando-lhes nos pés, na expectativa de ouvir a língua engrolada, só encontraram um olhar pálido e uma boca crispada (RAWET, 2004, p. 31).

A mulher não é vista integralmente nem a ela é dedicado respeito ou tolerância. $\mathrm{O}$ narrador exibe suas múltiplas faces como a um cubo. Não há uma descrição realista, mas uma descrição que deforma a figura, o que corresponde ao enviesamento do olhar xenófobo dos

\footnotetext{
A obra de Rawet suscita uma reflexão sobre a parca recepção crítica na década de 1950 ou mesmo sobre o apagamento por que passou em décadas subsequentes. Enquanto Lasar Segall, citado mais adiante neste artigo, é bem recebido, encontra aqui um crítico do porte de Mário de Andrade cujos estudos sobre o Expressionismo permitiram a compreensão e o destaque para uma obra como a do pintor; Rawet publica sua obra inaugural em 1956, mesmo ano da publicação da obra de grande sucesso de crítica, o Grande sertão: veredas, de Guimarães Rosa. O outro para a literatura neste momento é o sertanejo, o homem do interior que já vinha recebendo nomeada atenção na literatura brasileira desde a década de 1930. Rawet era então conhecido como engenheiro partícipe da criação de Brasília.
}

meninos. Eles a tratam como um ser estranho a quem podem provocar com insultos e pedras. Xale, cabelo, pés, olhos, boca, as partes pelo todo, como dita o princípio elementar da sinédoque. O xale pela vestimenta, o coque pelo rosto, os pés, os olhos e a boca pelo corpo. São, sinédoque e metonímia, próximas ao cubismo, como já preconizou Jakobson também em relação a outras artes:

\begin{abstract}
(...) pode-se notar a orientação manifestadamente metonímica do Cubismo, que transforma o objeto numa série de sinédoques; os pintores surrealistas reagiram com uma concepção visivelmente metafórica. A partir das produções de D. W. Griffith, a arte do cinema, com sua capacidade altamente desenvolvida de variar o ângulo, a perspectiva e o foco das tomadas, rompeu com a tradição do teatro e empregou uma gama sem precedentes de grandes planos sinedóquicos e de montagens metonímicas em geral. Em filmes, como os de Charles Chaplin e Eisenstein, esses procedimentos foram suplantados por um novo tipo metafórico de montagem, com suas 'fusões superpostas' - verdadeiras comparações fílmicas (JAKOBSON, 1975, p. 58).
\end{abstract}

Guiando-nos pelo olhar do voyeur, o narrador dele se distancia: quanto mais cruéis se mostram os meninos, mais sobressai sua solidariedade para com a personagem. O "efeito do real" aqui é substituído por rápidas tomadas que têm a função de dizer aquilo que os meninos veem de forma deturpada. $\mathrm{E}$, se pensarmos na sinédoque como um recurso cinematográfico, também outra convocação se encontra aí.

\section{Das mediações, da moldura, do retrato}

É sob esse mesmo olhar que o leitor tem conhecimento do ritual da prece. Ao tentar descansar depois de uma sexta-feira estafante, a protagonista prepara o quarto para a oração do shabat. O movimento do exterior para o interior se dá pela mediação da janela e pela curiosidade dos meninos, novamente postos frente a uma situação de estranhamento. $\mathrm{O}$ ritual não lhes era familiar, por isso deveria ser coisa de outro mundo, passível de averiguação e até de interdição.

- Tu viu?

- Vi!... A gringa tinha um jeito esquisito! ...

- Tu foi trouxa! ... Devia dar pedra na janela.

- Não chateia! Estou é invocado com um troço...

(...)

A revelação de Brito estarreceu a meninada. Uns olhos desconfiados, meio a medo, fitavam a janela no canto do sobrado. Um gosto de aventura e um pingo de lembrança de história contada, deixou-os estatelados. Negrinho João, oito anos feitos, coçando a cabeça, deu o jeito.

- O melhor é a gente dizer pro pessoal lá dentro! (RAWET, 2004, p. 34). 
Mediadora entre o espaço público e o espaço privado, a janela também pode exercer a função de moldura. Assim, encontra-se aqui outro recurso ao pictural: as bordas de um quadro esdrúxulo para os personagens colocam Ida sob uma posição estática do ponto de vista do olhar sobre o estrangeiro, embora ela estivesse no quarto preparando delicadamente a sua cerimônia. A marca pictural do enquadramento, recurso que limita o olhar ao quarto da protagonista ressalta mais uma convocação aos elementos visuais. Dele se pode extrair um dos aspectos da estereotipia. Como ensina Homi Bhabha (2005), o estereótipo assenta-se na fixidez, na repetição e na ambivalência. Se o Outro me é inferior, e isso se transforma em coisa dada, naturalizada, fixá-lo em uma moldura ou repetir à exaustão sua negatividade reforçam o estereótipo em que o enquadro. Janela e moldura, divisão entre o mundo que espia espantado e o mundo que é espiado.

Mas não basta espiar, o conto vai além. Na cena seguinte, crianças e adultos invadem o espaço privado em que a personagem reza. Não mais, o olhar curioso se mostra aí, mas os olhares inquisidores, invasivos que adentram o quarto de Ida. Em uma radical negativa da alteridade por parte dos vizinhos, a personagem se vê cerceada na sua privacidade:

Hoje, Ida não pedia a Deus, mas com as mesmas palavras, gritava, ofendia. Não sentiu o ruído nem as pancadas. A porta estava encostada e não foi preciso arriá-la. A voz quente, compassada, não a deixou ver a multidão que ia lhe enchendo o quarto, em atropelo. (RAWET, 2004, p. 34-35)

Não há mais mediação, a porta, o espaço intervalar, estava entreaberto e facilitou a entrada, o que não quer dizer que os vizinhos não entrariam à força, como mostra o narrador. A personagem não esboça reação, concentrada que está na prece. "Tinha entre os olhos e a palma das mãos, plasmados no escuro, o rosto de Isaías e dos filhos, de Isaías, quase um santo" (RAWET, 2004, p. 35). Pode-se ler essa apatia da personagem como um momento de choque entre sua interioridade que expressa naquele momento a identidade judaica pela religião e a profunda solidão em que se encontra, ou como a indiferença em que se deixa ficar o estrangeiro, conforme diz Kristeva.

A animosidade suscitada pelo estrangeiro, ou no mínimo a irritação ("O que você está fazendo aqui? "Aqui não é o seu lugar!") pouco o surpreendem. De bom grado ele sente uma certa admiração para com os que o acolheram, pois em geral acredita serem eles superiores, seja material, política ou socialmente. Ao mesmo tempo não deixa de julgá-los um pouco limitados, cegos. Pois os seus anfitriões desdenhosos não possuem a distância que ele possui, para se ver e para vê-los. O estrangeiro fortifica-se com esse intervalo que o separa dos outros e de si mesmo, dando-lhe um sentimento altivo, não por estar de posse da verdade, mas por relativizar a si próprio e aos demais, quando estes encontram-se nas garras da rotina da monovalência. Os outros talvez possuam coisas, mas o estrangeiro sabe que ele é o único a ter uma biografia, isto é, uma vida feita de provas. Nada como catástrofes ou aventuras (embora umas quanto as outras possam acontecer), simplesmente uma vida onde os atos são acontecimentos, porque implicam escolhas, surpresas, rupturas, adaptações ou estratagemas, sem rotina ou repouso. Aos olhos do estrangeiro, os que não o são não tem vida alguma: mal existem, sejam esplêndidos ou medíocres, estão fora da corrida e, portanto, quase já corpos sem vida (KRISTEVA, 1994, p. 14-15).

É da história de Ida história que nos fala outra marca pictural: o retrato. No quarto exíguo onde cabem a cama, um pedaço de cômoda-guarda-roupa e o fogareiro, a fotografia na parede condensa um mundo e uma parte da história de Ida, da guerra e dos imigrantes judeus. É a partir dos olhos de Isaías em prece que é possível ao narrador lançar a rememoração.

Na parede os olhos de Isaías, em prece, assustaram-se com o tlic da fotografia. Ida lembrou o esforço para convencê-lo a deixar o retrato, conseguido de surpresa. Agora pendia amarelado, a mancha da barba, as sobrancelhas arqueadas e uns olhos de susto. Que pesadelo! Isaías às sextas-feiras entrava mais alegre, $\mathrm{o}$ rosto brilhando, e um ou outro pingo d'água, da barba, denunciava o banho. Dava umas palmadas em suas costas (Ida tinha o rosto vermelho da lenha do forno), e ia orar. Agora, o retrato.

(...)

De tudo, só o retrato ficou na parede. E ela. No rosto marcado de rugas, um sofrimento triturado. Esquecia. Morreram-lhe todos com a guerra. A tampa da panela ritmava o samba do rádio, agitada pelo vapor. Sem saber como saltou um dia no porto daqui. Deixava uma existência inteira atrás (RAWET, 2004, p. 33).

A fotografia de um único membro da família lembra a Ida a perda de todos eles, marido e filhos, os ausentes que se fazem presentes pelo amarelado da fotografia e pela mancha da barba, marcas da deterioração e da ação do tempo. A descrição da fotografia, portanto, abre com esses poucos recursos uma reflexão sobre a viagem, sobre a história belicista do século XX, sobre a perseguição nazista, sobre os aniquilamentos. A imagem atravessa o oceano e conduz até o quarto minúsculo o corpo dentro do espaço e a ação ao longo do tempo, uma das transições entre as artes. 
Não pertencer a nenhum lugar, nenhum tempo, nenhum amor. A origem perdida, o enraizamento impossível, a memória imergente, o presente em suspenso. O espaço do estrangeiro é um trem em marcha, um avião em pleno ar, a própria transição que exclui a parada. Pontos de referência, nada mais. O seu tempo? O de uma ressureição que se lembra da morte e do antes, mas perde a glória do estar além: somente a impressão de um sursis, de ter escapado (KRISTEVA, 1994, p. 15).

Ida cumpre ali outras penas, a da intolerância, a da dificuldade de comunicação, a da hostilidade, a da estereotipia.

\section{Face expressionista}

Em meio aos barulhos do casarão: algazarra, gritos, cantorias, sambas no rádio, ave-maria no andar de cima, a personagem permanece estática. Tal é a composição de outra cena, posterior à do retrato: "A luz de um lampião, na calçada, cortou o rosto de Ida em dois, em diagonal. Um olho truncado pelo clarão brilhava em seco" (RAWET, 2005, p. 33). Nota-se o recurso pictural pelo emprego vocabular que marca a linha e a iluminação. Além disso, como não reconhecer na descrição acima uma imagem expressionista? Como não ver ali um retrato dos tantos pintados por Lasar Segall, judeu, nascido em Vilna na Lituânia, que veio para o Brasil no entreguerras, já com larga experiência nos efeitos da destruição da Europa e com consistente conhecimento da vanguarda europeia. Entretanto, não é pela mera correspondência que a picturalidade se mostra aí. Posso aproximá-lo, como leitora, das obras Morte (1917), Duas crianças (1919), Autorretrato II (1919), Interior de pobres II (1921) e de tantas outras que compõem o acervo segalliano. Mais especificamente, é possível destacar a tela Autorretrato II, em que o pintor vê a si mesmo com o rosto cortado em diagonal, formando um desequilibrado triângulo no qual um olho aparece esvaziado em cor amarela e outro, o da esquerda, parece contemplar o espectador. As cores em tons de ocre, amarelo, preto e marrom contribuem para a atmosfera deformada do retrato assim como as linhas da testa indicam a severidade das rugas. Esse recorte intertextual foi possibilitado pela convocação que a descrição rawetiana sugere. Não sabemos se o autor tinha em mente uma tela expressionista, contudo podemos sugerir a categoria da descrição de uma tela que não existe, mas que pode ser associada a um estilo, a um movimento a obras semelhantes (LOUVEL, 2006).

O Expressionismo, como a exteriorização de um estado interior de consciência, foi um movimento artístico que se expandiu em meio à Primeira Guerra Mundial e que questionou os motivos pelos quais a sociedade deixou emergir o conflito. $\mathrm{O}$ artista explora a deformação, não a imitação. É uma arte que tem um compromisso ético com o ser humano, uma arte social penhorada em contestar a face trágica da guerra, das perseguições, dos aniquilamentos. Em Segall, como frisou o crítico Rodrigo Naves, há um movimento de empatia que o afasta da "separação instransponível entre subjetividades exacerbadas e um real indiferente" (NAVES, 2011, p. 207-209). Segundo ele, a paleta do pintor "apenas aponta os limites daquela polarização e vê na simplicidade uma maneira de se encontrar um termo comum entre a extrema singularidade dos indivíduos e as exigências dos processos objetivos" (ibid., p. 209).

\section{Considerações finais}

É dessa simplicidade e economia que nos fala o conto de Rawet. A crítica recente a sua obra tem destacado essas características. Berta Waldamann aponta para a estratégia empregada por Rawet para marcar o isolamento dos personagens, bem como os recursos utilizados para narrar uma história:

\begin{abstract}
o narrador raras vezes thes passa a palavra, construindo-as à sombra da elipse, fazendo-as, além disso, contracenar com figuras pálidas e esmaecidas, apenas esboçadas, alcançando, pelo desnível de tratamento, trancar ainda mais os protagonistas em sua subjetividade. Marcando sua solidariedade com aquele que sofre, o narrador recorta a frase permeando-a de pausas, para criar no plano estilístico uma homologia do que é contado. Chama a atenção o uso de um amplo vocabulário, a obsessiva preocupação com a palavra precisa, a capacidade de dotar a linguagem de notações plásticas, sendo que o conjunto assinala a franca superação da barreira linguística que aquele que veio de fora teve de enfrentar (2003, p. 72).
\end{abstract}

As marcas da picturalidade ancoram a construção da personagem Ida. A posição do narrador que ora espreita por intermédio da visão dos vizinhos ora por seus próprios olhos é fundamental para marcar essa ideia de empatia com que se constrói o texto. A recorrência a tantos aspectos visuais permite registrar, além do efeito da translação, o contexto histórico-cultural de onde emerge. Essa combinação entre os marcadores aqui explicitados, elementos internos e estruturantes do conto, com a articulação contextual suscita uma reflexão sobre a imagem do imigrante partida e deformada, seja por meio do olhar a ele lançado, seja pela fixidez da moldura e dos enquadramentos em que se quer fixá-lo. As zonas cinzentas, os objetos recalcitrantes $-o$ retrato amarelado, os olhos de susto, a mancha da barba, as sobrancelhas arqueadas, o olho pálido, o olho truncado entre outros marcadores - nos convocam, em chave metonímica, para a representação dos movimentos migratórios no Brasil em sua face excludente, intolerante, hostil e estereotipada. 


\section{Referências}

BANDEIRA, Manuel. Estrela da vida inteira. Rio de Janeiro: Nova Fronteira, 1993.

BHABHA, Homi. O local da cultura. Tradução Myriam Ávila et al. Belo Horizonte: Editora UFMG, 2005.

BINES, Rosana Kohl. Modos de desconexão: a crítica brasileira e a obra de Samuel Rawet. In: Dez ensaios sobre Samuel Rawet. Brasília: LGE, 2007. p. 55-71.

CHIARELLI, Stefania. Flauta, pandeiro e violão: Samuel Rawet, escritor brasileiro. In: Dez ensaios sobre Samuel Rawet (Org. Saul Kirschbaum). Brasília: LGE, 2007. p. 89-100.

CLÜVER, Claus. Estudos interartes - conceitos, termos, objetivos. Trad. de Claus Clüver e Samuel Titan Jr. Literatura e sociedade - Revista de teoria literária e literatura comparada (Universidade de São Paulo), n. 2, p. 37-55, 1997.

CLÜVER, Claus. Intermidialidade e estudos interartes. Encontro Regional da ABRALIC - Literatura, artes, saberes. Org. Sandra Nitrini et al. São Paulo: Aderaldo \& Rothschild, ABRALIC, 2008. p. 209-232.

CURY, Maria Zilda. Navio de imigrantes, identidades negociadas. São Paulo: Fundação Memorial da América Latina, 2002. (Coleção Memo Ensaio/Ficção). p.21-22.

IGEL, Regina. Imigrantes judeus/escritores brasileiros: o componente judaico na literatura brasileira. São Paulo: Perspectiva, 1997

JAKOBSON, Roman. "Dois aspectos da linguagem e dois tipos de afasia”. In: Linguística e comunicação. Trad. de Izidoro Blikstein e José Paulo Paes. São Paulo: Cultrix, 1975.
KRISTEVA, Julia. Estrangeiros para nós mesmos. Trad. de Maria Carlota Carvalho Gomes. Rio de Janeiro: Rocco, 1994.

LOUVEL, Liliane. "A descrição "pictural"”. Por uma poética do iconotexto. In: ARBEX, Márcia (Org.). Poéticas do visivel: ensaios sobre a escrita e a imagem. Belo Horizonte: Programa de Pós-Graduação em Letras, Estudos Literários/Faculdade de Letras da UFMG, 2006. p. 191-220.

NAVES, Rodrigo. Expressão e compaixão nos desenhos de Segall. In: A forma difícil - ensaios sobre arte brasileira. São Paulo: Companhia das Letras, 2011. p. 201-231.

RAWET, Samuel. Contos e novelas reunidos. Rio de Janeiro: Civilização Brasileira, 2004.

RAWET, Samuel. Ensaios reunidos. (Org. Rosana Kohl Bines e José Leonardo Tonus). Rio de Janeiro: Civilização Brasileira, 2011.

SOUSA, Gilda de Melo; CANDIDO, Antonio. Prefácio. In: BANDEIRA, Manuel. Estrela da vida inteira. Rio de Janeiro: Nova Fronteira, 1993.

WALDMAN, Berta. Noturno suburbano. In: Entre passos e rastros: presença judaica na literatura brasileira contemporânea. São Paulo: Perspectiva: FAPESP: Associação Universitária de Cultura Judaica, 2003. p. 67-100.

WALDMAN, Berta. Caminhos cruzados: a segunda guerra mundial em dois tempos. In: Visões de guerra: Lasar Segall. Textos de Celso Lafer, Berta Waldman e Jorge Coli. São Paulo: Imprensa Oficial do Estado de São Paulo: Museu Lasar Segall: Centro de Cultura Judaica, 2012. p. 121-131.

Recebido: 17/11/16

Aprovado: 21/03/17

Contato: isabel.edom@gmail.com 